\title{
What is the Clinical Parameter Affecting the Quality of Life in Lung Transplant Candidates?
}

\author{
Esra Pehlivan* \\ Department of Physiotherapy and Rehabilitation, Faculty of Health Sciences, Health Sciences University, Istanbul, Turkey
}

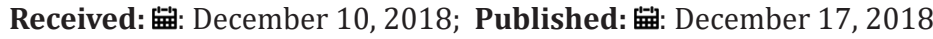

*Corresponding author: Esra Pehlivan, Department of Physiotherapy and Rehabilitation, Faculty of Health Sciences, Health Sciences University, Istanbul, Turkey

\section{Abstract}

Introduction: There are many clinical parameters affecting the quality of life in terminal period respiratory patients planned for lung transplantation. The aim of this study was to determine the main clinical features of lung transplantation candidates responsible for the deterioration of quality of life.

Method: Forty-three lung transplantation candidates referred to our clinic for preoperative pulmonary rehabilitation program were included in the study. Study outcome measurements: Saint George Quality of Life Questionnaire (SGRQ), modified Medical Research Council Dyspnea score (mMRC), 6-minute walk test distance (6MWD), maximal inspiratory pressure (MIP), digital peripheral muscle strength measurements, hang grip strenght (HG) and lung function test parameters. The correlation between SGRQ total score and other clinical parameters were examined.

Results: The mean age of the patients was $38.02(14-68)$ and $62.8 \%(n=27)$ were male. There was a high correlation between biceps muscle strength ( $\mathrm{p}<.0001, \mathrm{r}=.606)$ and 6MWD ( $\mathrm{p}<.0001, \mathrm{r}=.647)$ with SGRQ total score. And also HG ( $\mathrm{p}=.005, \mathrm{r}=.450)$, dorsiflexion muscle strenghts ( $\mathrm{p}=.001$, $\mathrm{r}=.508)$, MIP ( $\mathrm{p}=.002, \mathrm{r}=.489)$, and mMRC ( $\mathrm{p}<.0001, \mathrm{r}=.578)$ were moderately correlated with SGRQ. Correlation with respiratory functions and quality of life was found to be lower.

Discussion: Lung transplantation candidates have many clinical features that determine quality of life. In our study, It has been found that quality of life is more affected by peripheral and respiratory muscle strength, exercise capacity and dyspnea perception rather than respiratory function. This should be taken into account when planning pulmonary rehabilitation programs.

Keywords: Exercise Capacity; Exercise Test; Dyspnea; Muscle Strenght; Pulmonary Rehabilitation

Abbreviations: SGRQ: Saint George Quality of Life Questionnaire; mMRC: modified Medical Research Council Dyspnea score; 6MWD: 6-Minute Walk Test Distance; MIP: Maximal İnspiratory Pressure; HG: Hang Grip Strength; PR: Pulmonary Rehabilitation; ATS: American Thoracic Society; SPSS: Statistical Package for Social Sciences; ERS: European Respiratory Society

\section{Introduction}

The quality of life in terminal stage lung disease patients is greatly reduced by both advanced lung pathology and negative effects of immobilization. Improving health-related quality of life is an important goal of lung transplantation (LTx) [1]. In chronic respiratory patients, Pulmonary Rehabilitation (PR) increases exercise capacity, reduces dyspnea, improves muscle strength and increases psychological well-being [2]. It has been also shown that PR has a positive effect on quality of life in LTx candidates [3]. However, in the literature, there is no study on which clinical feature affects the quality of life in this patient population. In our study, clinical features affecting the quality of life of LTx candidates were examined. We believe that it would be useful to consider the clinical features affecting the quality of life in the design of the PR programs.

\section{Method}

This study was retrospective cohort study. Between October 2015 and March 2017, the patients with severe lung disease who had previously referred to outpatient hospital-based PR program and had inclusion criterias were taken and their data were analyzed retrospectively. The patients were eligible for inclusion if participitants have: a diagnosis of terminally severe lung disease, being listed for lung transplantation and refered to PR exercise program. The study was approved by the Local Ethics Committee, conducted in accordance with the Helsinki Declaration. A written informed consent was obtained from each patient before the Pulmonary rehabilitation program. 


\section{Outcome Measurements}

All measurements were performed by the same physiotherapist before the patient started the PR program. Quality of life was assessed based on The Saint George Respiratory Questionnaire (SGRQ). The questionnaire has been designed specifically for respiratory patients [4]. It is a standardized self-completed questionnaire for measuring impaired health and perceived wellbeing ('quality of life') in airways disease [5]. The SGRQ ranges from 0 (no impairment of quality of life) to 100 (highest impairment of quality of life). Dyspnea was assessed based on modified Medical Research Council's (mMRC) dyspnea scale [6]. Exercise capacity was also assessed by six-minute walking test (6MWT) based on the American Thoracic Society (ATS) standards [7]. The pulmonary function test was conducted using a Sensor Medics model 2400 device (Yorba Linda, CA, USA), in line with American Thoracic Society (ATS) guidelines [8]. The mouth pressure measurement was performed using a Micro-RPM® instrument of Sensor MEDI [9]. The peripheral muscle strength was measured using a digital dinanometer (J-Tech Medical; Utah, USA), with three measurements made in total of the tibialis anterior, quadriceps femoris and biceps brachia. Hand grip strength was measured using Baseline hydraulic hand dynamometer (Fabrication Enterprises; New York, USA).

\section{Statistical Analysis}

Statistical analyses of the study were performed using Statistical Package for Social Sciences (SPSS) Version IBM Statistic 15.0 (SPSS Inc. Chicago, IL, USA). Demographic and clinical characteristics of all subjects were summarized descriptively. Variables were expressed as median, minimum and maximum. Pearson's correlation test was used to verify the relationship between outcome parameters. $\mathrm{p}<0.05$ was considered statistically significant.

\section{Results}

The mean age of the patients was 38.02 (14-68) and 62.8\% $(n=27)$ were male. Demographic and clinical characteristics of the patients are given in Table 1 . There was a high correlation between biceps muscle strength ( $\mathrm{p}<.0001, \mathrm{r}=.606), 6 \mathrm{MWD}(\mathrm{p}<.0001, \mathrm{r}=.647)$ and mMRC dyspnea score ( $\mathrm{p}<.0001, \mathrm{r}=.578)$ with SGRQ. And also HG $(\mathrm{p}=.005, \mathrm{r}=.450)$, dorsiflexion $(\mathrm{p}=.001, \mathrm{r}=.508)$, MIP $(\mathrm{p}=.002$, $\mathrm{r}=.489)$, and mMRC $(\mathrm{p}<.0001, \mathrm{r}=.578)$ was moderately correlated with SGRQ. Correlation with respiratory functions and quality of life was found to be lower. All correlations were given in Table 2.
Table 1: Demographic and clinical characteristics of patients.

\begin{tabular}{|c|c|}
\hline & Median (Min-Max) \\
\hline $\begin{array}{c}\text { Demographic features } \\
\text { Age, year } \\
\text { Gender (female } / \text { male })(\%, \mathrm{n}) \\
\text { BMI, kg/m² }\end{array}$ & $\begin{array}{c}38.02(14-68) \\
62.8 / 37.2(27 / 16) \\
21.15(12-33)\end{array}$ \\
\hline $\begin{array}{c}\text { Diagnosis } \\
\text { Alveolar proteinosis } \\
\text { Bronchiectasis } \\
\text { ILD }\end{array}$ & $\begin{array}{c}1(2.3) \\
18(41.9) \\
3(7.0)\end{array}$ \\
\hline Kartagener Syndrome & $1(2.3)$ \\
\hline Cystic fibrosis & $5(11.6)$ \\
\hline COPD & $9(20.0)$ \\
\hline RA lung involvement & $1(2.3)$ \\
\hline Sarcoidosis & $2(4.7)$ \\
\hline Silicosis & $3(7.0)$ \\
\hline $\begin{array}{l}\text { Quality of life } \\
\text { SGRQ total score }\end{array}$ & $66.00(24-96)$ \\
\hline Peripheral muscle strenght (lbs) & \\
\hline Quadriceps femoris & $40.03(14-74)$ \\
\hline Tibialis anterior & $38.86(11-73)$ \\
\hline Biceps & $10-67(33.33)$ \\
\hline Hand grip & $60.30(30-108)$ \\
\hline $\begin{array}{c}\text { Solunum kas kuvveti } \\
\text { MIP, } \mathrm{H}_{2} \mathrm{O}\end{array}$ & $74.46(12-129)$ \\
\hline $\begin{array}{l}\text { Dyspnea severity } \\
\operatorname{mMRC}(1-4)\end{array}$ & $3(1-4)$ \\
\hline $\begin{array}{l}\text { Lung functions } \\
\text { FVC(\%perdicted) } \\
\text { FEV1(\%perdicted) } \\
\text { FEV1/FVC }\end{array}$ & $\begin{array}{c}40.62(18-72) \\
32.49(10-63) \\
70.00(35-110)\end{array}$ \\
\hline $\begin{array}{c}\text { Exercise capacity } \\
\text { 6-MWD(m) }\end{array}$ & $338.24(42-548)$ \\
\hline
\end{tabular}

BMI: Body mass index; ILD: Interstisiel lung disease; COPD: Chronic obstructive pulmonary disease; SGRQ: Saint George Respiratory Questionnaire; MIP: Maximal inspiratory pressure; mMRC: modified Medical Research Council Association dyspnea score; 6MWD: 6-minute walking distance; FVC: Forced vital capacity; FEV1: forced expiratory volume in 1 second.

Table 2: Correlations of quality of life and other clinical parameters.

\begin{tabular}{|c|c|c|c|c|c|c|c|c|c|c|}
\hline & QF & Biceps & HG & DorsiFlx & MIP & 6MWD & mMRC & FVC\% & FEV1\% & FEV1/FVC \\
\hline $\mathrm{SGRQ}_{\text {Total }}$ & -.349 & -.606 & -.450 & -.508 & -.489 & -.647 & .578 & -.386 & -.334 & -.009 \\
$\mathrm{r}$ & .034 & .000 & .005 & .001 & .002 & .000 & .000 & .018 & .043 & .957 \\
$\mathrm{p}$ & & & & & & & & \\
\hline
\end{tabular}

SGRQ: Saint George Respiratory Questionnaire; QF: Quadriceps muscle strenght; Biceps: biceps muscle strength; HG: Hand Grip muscle strength; DorsiFlx: Dorsiflexion muscle strenght; MIP: Maximal inspiratory pressure; mMRC: modified Medical Research Council Association dyspnea score; 6MWD: 6-minute walk distance; FVC: Forced vital capacity; FEV1: forced expiratory volume in 1 second. 


\section{Discussion}

Our study was a retrospective cross sectional study. This study results showed that quality of life is more affected by exercise capacity, dyspnea perception, peripheral and respiratory muscle strength rather than respiratory functions. Lung Transplantation has the potential to extend life time. But if a successful LTx is mentioned, the quality of life should be increased [10]. A crosssectional study indicated that lung transplant patients must cope with the side effects of immunosuppression after operation. But the mentioned study results reported a highly satisfying quality of life with regard to physical and emotional well-being and social and sexual function [11].

The cause of the decline in quality of life in patient with terminaly ill lung disease requiring lung transplantation patients is not clear. In a prospective cohort study, researchers indicated that LTx confers HRQL benefits. The authors showed that this benefits changes due to diagnosis [12]. In a review, bronchiolitis obliterans syndrome has been reported to have some adversely affects on health related quality of life [13]. On the other hand some researchers who offer 20 years of experience in a single center reported that bronchiolitis obliterans syndrome and sepsis still limit the durability of the benefit, but lung transplantation returns many patients with end-stage lung disease to active and productive lives [14]. Another study showed that there was less HRQL benefit in interstitial lung disease than in cystic fibrosis [12]. In our study, although the diagnosis of the patients were variable, patients were predominantly diagnosed with bronchiectasis. Because of the limited number of patients, sub-group analysis of the factors affecting the quality of life could not be performed. The age may affect post-transplant gains. In particular, it was reported that the age of the older people over 65 years of age was a factor that hampered the increase in quality of life [15]. A study showed that age was not associated with meaningful differences in the HRQL benefits of transplantation but older age may effect the outcomes [12]. In our study, the patient age range was between 14 and 68 years. The mean age was 38 years. There were only 1 patient over the age of 65 years. We think this does not affect the study results.

The muscle dysfunction is a main systemic consequence of chronic respiratory diseases. However, there are still important gaps in our knowledge about this issue [16]. And also the muscle strength is an important parameter affecting quality of life. There are studies showing that quadriceps femoris muscle strength may be a predictor of mortality in chronic respiratory patients [17]. Existing lung pathology and immobilization increase muscle strength loss. In a study of patients with interstitial lung disease, weakness and atrophy of the lower extremity muscles were detected [18]. In a review containing six studies, authors detected none of them evaluated upper and lower extremity muscle strength. Nonetheless, rehabilitation has been proven to also improve limb muscle function in patients with lung disease such as COPD [16]. A statement from American Thoracic Society (ATS) and European Respiratory Society (ERS) highlighted that quadriceps muscle strength, endurance and fatigability improved significantly after exercise training in patients with COPD [16]. This mentioned study proved that resistance training significantly improved knee extension strength and that this could be related to better exercise capacity and reduced dyspnoea [16]. In our study, the relationship between quality of life and peripheral muscle strength was determined. When the lower and upper extremity muscle strengths were examined separately, Biceps muscle strength was found to be more effective but the hand grip strength was found to be moderately effective same as dorsiflexion muscle strength.

Respiratory muscle strength is an issue that has been emphasized in recent years. It is an important factor that decreases exercise capacity [19] and increases dyspnea [20] in chronic respiratory patients. The inspiratory metaboreflex is activated during loaded breathing to task failure and induces sympathetic activation and peripheral vasoconstriction that may limit exercise performance [21]. In a randomized controlled trial of inspiratory muscle training in lung transplant candidates, a further increase in exercise capacity of the group without inspiratory muscle training was found [22]. In our literature review, we did not find any study examining the effect of inspiratory muscle strength on quality of life. The patient population in our study did not have respiratory muscle weakness. Studies on quality of life effects of groups with and without respiratory muscle weakness are needed. Pulmonary rehabilitation improves exercise capacity, reduces the sensation of dyspnea and muscle strength loss, and has a positive effect on quality of life and the psychologic state of patients who are candidates for lung transplant [2,3]. Specific exercise programs are not included in the guidelines for this patient group. We believe that the factors affecting quality of life will be helpful for clinicians in determining pulmonary rehabilitation program design and medical treatment.

\section{References}

1. Singer JP, Singer LG (2013) Quality of life in lung transplantation. Seminars in respiratory and critical care medicine 34(3): 421-430.

2. Pehlivan E, Balci A, Kilic L, Kadakal F (2018) Preoperative Pulmonary Rehabilitation for Lung Transplant: Effects on Pulmonary Function, Exercise Capacity, and Quality of Life; First Results in Turkey. Experimental and clinical transplantation: Official journal of the Middle East Society for Organ Transplantation. 16(4): 455-460.

3. Florian J, Rubin A, Mattiello R, Fontoura FF, Camargo Jde J, et al. (2013) Impact of pulmonary rehabilitation on quality of life and functional capacity in patients on waiting lists for lung transplantation. Jornal brasileiro de pneumologia: Publicacao oficial da Sociedade Brasileira de Pneumologia e Tisilogia 39(3): 349-356.

4. Jones PW, Quirk FH, Baveystock CM, Littlejohns P (1992) A self-complete measure of health status for chronic airflow limitation. The St. George's Respiratory Questionnaire. The American review of respiratory disease 145(6): 1321-1327.

5. Jones PW, Quirk FH, Baveystock CM (1991) The St George's Respiratory Questionnaire. Respiratory medicine 85: 25-31.

6. Bestall JC, Paul EA, Garrod R, Garnham R, Jones PW, et al. (1999) Usefulness of the Medical Research Council (MRC) dyspnoea scale as a measure of disability in patients with chronic obstructive pulmonary disease. Thorax 54(7): 581-586.

7. (2002) ATS statement: Guidelines for the six-minute walk test. American journal of respiratory and critical care medicine 166(1): 111-117. 
8. Miller MR, Crapo R, Hankinson J, Brusasco V, Burgos F, et al. (2005) General considerations for lung function testing. The European respiratory journal 26(1): 153-161.

9. American Thoracic Society/European Respiratory S (2002) ATS/ERS Statement on respiratory muscle testing. American journal of respiratory and critical care medicine 166(4): 518-624.

10. Kolaitis NA, Singer JP (2018) Defining Success in Lung Transplantation: From Survival to Quality of Life. Seminars in respiratory and critical care medicine 39(2): 255-268.

11. Smeritschnig B, Jaksch P, Kocher A, Seebacher G, Aigner C, et al. (2005) Quality of life after lung transplantation: A cross-sectional study. The Journal of heart and lung transplantation: The official publication of the International Society for Heart Transplantation 24(4): 474-480.

12. Singer LG, Chowdhury NA, Faughnan ME, Granton J, Keshavjee S, et al. (2015) Effects of Recipient Age and Diagnosis on Health-related Qualityof-Life Benefit of Lung Transplantation. American journal of respiratory and critical care medicine 192(8): 965-973.

13. Singer LG (2004) Cost-effectiveness and quality of life: Benefits of lung transplantation. Respiratory care clinics of North America 10(4): 449457.

14. De Perrot M, Chaparro C, McRae K, Waddell TK, Hadjiliadis D, et al. (2004) Twenty-year experience of lung transplantation at a single center: Influence of recipient diagnosis on long-term survival. The Journal of thoracic and cardiovascular surgery 127(5): 1493-1501.

15. Singer JP, Katz PP, Soong A, Shrestha P, Huanq D, et al. (2017) Effect of Lung Transplantation on Health-Related Quality of Life in the Era of the Lung Allocation Score: A U.S. Prospective Cohort Study. American journal of transplantation: Official journal of the American Society of Transplantation and the American Society of Transplant Surgeons 17(5): 1334-1345.

\section{ISSN: 2574-1241}

DOI: 10.26717/BJSTR.2018.12.002220

Esra Pehlivan. Biomed J Sci \& Tech Res

(C) (P) This work is licensed under Creative

BY Commons Attribution 4.0 License

Submission Link: https://biomedres.us/submit-manuscript.php
16. Maltais F, Decramer M, Casaburi R, Barriero B, Burelle Y, et al. (2014) An official American Thoracic Society/European Respiratory Society statement: Update on limb muscle dysfunction in chronic obstructive pulmonary disease. American journal of respiratory and critical care medicine 189(9): 15-62.

17. Swallow EB, Reyes D, Hopkinson NS, William D, Raphael P, et al. (2007) Quadriceps strength predicts mortality in patients with moderate to severe chronic obstructive pulmonary disease. Thorax 62(2): 115-120.

18. Mendes P, Wickerson L, Helm D, Ferreira T, Brooks D, et al. (2015) Skeletal muscle atrophy in advanced interstitial lung disease. Respirology (Carlton, Vic.) 20(6): 953-959.

19. Gosselink R, Troosters T, Decramer M (1996) Peripheral muscle weakness contributes to exercise limitation in COPD. American journal of respiratory and critical care medicine 153(3): 976-980.

20. Hamilton AL, Killian KJ, Summers E, Jones NL (1995) Muscle strength, symptom intensity and exercise capacity in patients with cardiorespiratory disorders. American journal of respiratory and critical care medicine 152(6 Pt 1): 2021-2031.

21. Callegaro CC, Ribeiro JP, Tan CO, Taylor JA (2011) Attenuated inspiratory muscle metaboreflex in endurance-trained individuals. Respiratory physiology \& neurobiology 177(1): 24-29.

22. Pehlivan E, Mutluay F, Balci A, Kilic L (2018) The effects of inspiratory muscle training on exercise capacity, dyspnea and respiratory functions in lung transplantation candidates: a randomized controlled trial. Clinical rehabilitation 32(10):1328-1339.

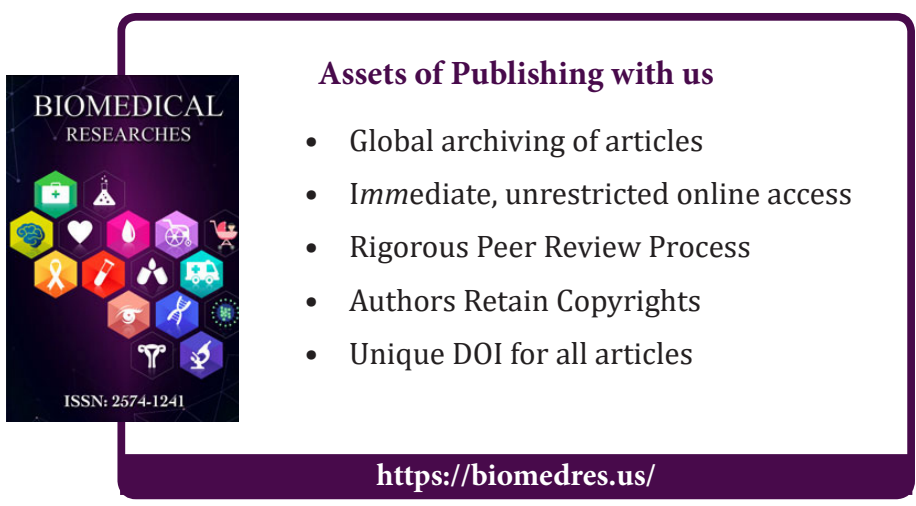

Cite this article:Esra Pehlivan. What is the Clinical Parameter Affecting the Quality of Life in Lung Transplant Candidates?. Biomed J Sci \& Tech 